\title{
AVALIAÇÃO DO PRÊMIO SEBRAE PREFEITO EMPREENDEDOR COMO ESTRATÉGIA DE DESENVOLVIMENTO ENDÓGENO: O CASO DO ESTADO DE ALAGOAS
}

\author{
EVALUATION OF THE SEBRAE ENTREPRENEUR MAYOR \\ AWARD AS AN ENDOGENOUS DEVELOPMENT STRATEGY: \\ THE CASE OF THE STATE OF ALAGOAS \\ Emerson Rodrigo Gomes Camêlo \\ Evandro Diego Alves Pinheiro \\ Fernando Coelho de Carvalho \\ Antônio Carlos Silva Costa
}

RESUMO: A implementação de práticas empreendedoras no âmbito dos entes e organizações públicas agrega um impacto significativo no desenvolvimento destes organismos, principalmente no aspecto econômico dos municípios brasileiros que, em sua grande maioria, passam ao largo da autossuficiência. No Brasil, várias instituições desempenham ações voltadas ao empreendedorismo em todos os níveis de governo, onde podemos destacar o Serviço Brasileiro de Apoio às Micro e Pequenas Empresas - Sebrae que em 2001 criou o Prêmio Sebrae Prefeito Empreendedor, premiando aqueles prefeitos que se sobressaem por implementar práticas inovadoras de inclusão na produção local. O presente artigo tem como objetivo avaliar se os municípios vencedores do Prêmio Sebrae Prefeito Empreendedor no estado de Alagoas apresentaram melhores resultados em indicadores que estão relacionados com políticas públicas de fomento ao empreendedorismo e ao desenvolvimento endógeno. Os resultados indicam que no intervalo entre 2012 e 2013, período de avaliação do prêmio, os municípios premiados tiveram em sua grande maioria resultados elevados tanto em relação aos períodos posteriores, quanto em relação aos dados estaduais. Entretanto, nos períodos posteriores, os resultados acompanharam os valores das médias do estado de Alagoas, ocorrendo pequenas variações.

Palavras-chave: Empreendedorismo; Políticas Públicas; Prêmio Sebrae Prefeito Empreendedor; Desenvolvimento Endógeno.

ABSTRACT: The implementation of entrepreneurial practices within public entities and organizations has a significant impact on the development of these organizations, mainly in the economic aspect of the Brazilian municipalities, which, for the most part, pass away from self-sufficiency. In Brazil, several institutions are involved in entrepreneurship actions at all levels of government, where we can highlight the Brazilian Service of Support to Micro and Small Businesses - Sebrae, which in 2001 created the Sebrae Entrepreneur Mayor Award, rewarding those mayors who excel at implementing innovative inclusion practices in local production. The purpose of this article is to evaluate whether the municipalities that won the Sebrae Entrepreneur Mayor Award in the state of Alagoas presented better results in indicators that are related to public policies to foster entrepreneurship and endogenous development. The results indicate that in the interval between 2012 and 2013, the evaluation period of the award, the municipalities awarded most had high 
results both in relation to the later periods, and in relation to the state data. However, in the later periods, the results followed the average values of the state of Alagoas, with small variations occurring.

KEYWORDs: Entrepreneurship; Public Policy; Sebrae Mayor Entrepreneur Award; Endogenous Development.

\section{INTRODUÇÃO}

Diante dos inúmeros conceitos do que vem a significar o termo empreendedorismo, pode-se defini-lo como sendo a descoberta de oportunidades e a subsequente criação de uma nova atividade econômica que resultam na criação de novas organizações, segundo o pensamento de Rocha e Sternberg (2005). O empreendedorismo tem como características o fato de ser inovador, inventor, criador de novas organizações e/ou atividades, utilizando-se de novos meios de produção inovadora e mais vantajosa.

É facilmente perceptível que a implementação de práticas empreendedoras no âmbito dos entes e organizações públicas agregaria um impacto significativo no desenvolvimento destes organismos, principalmente no aspecto econômico dos municípios brasileiros que, em sua grande maioria, passam ao largo da autossuficiência, necessitando de transferências de recursos ou da atuação direta dos estados e do governo federal para garantirem a prestação de serviços considerados básicos e fundamentais.

A implementação de políticas públicas de empreendedorismo acarreta no surgimento do desenvolvimento endógeno, considerado um modelo de desenvolvimento eficaz, em que as localidades deixam de depender em parte do auxílio externo, passando a criar soluções internas para suprirem as dificuldades regionais, utilizando-se da população local para influenciar no planejamento estratégico, priorizando o seu próprio potencial, trazendo o progresso aos empreendimentos e ao mercado regional, por meio do fomento e do acúmulo de recursos econômicos.

No Brasil, várias instituições desempenham ações voltadas ao empreendedorismo em todos os níveis de governo, em que podemos destacar o Serviço Brasileiro de Apoio às Micro e Pequenas Empresas Sebrae que, em suas categoria de premiações concedidas, promove um instrumento de motivação no mercado brasileiro. Seu objetivo principal é ajudar na implementação e no desenvolvimento de pequenas empresas e, para que isso ocorra, é fundamental que os governos participem propagando incentivos ao empreendedorismo nos municípios.

O Sebrae criou em 2001 o Prêmio Sebrae Prefeito Empreendedor, abrangendo todas as regiões do Brasil. A cada 2 (dois) anos prefeitos que se sobressaem por implementarem práticas inovadoras de inclusão na produção local, proporcionando oportunidades de inserção do cidadão no mercado de trabalho, com padrão de qualidade e equidade na distribuição de renda, serão agraciados com a premiação. 
O presente artigo tem como objetivo avaliar se os municípios vencedores do Prêmio Sebrae Prefeito Empreendedor no estado de Alagoas apresentaram melhores resultados em indicadores que estão relacionados com políticas públicas de fomento ao empreendedorismo e ao desenvolvimento endógeno. Para isso serão avaliados os resultados dos municípios ao longo de um período anterior e posterior à premiação, utilizando os resultados do estado de Alagoas como critério de comparação.

A metodologia adotada foi a de pesquisa documental, descritiva, utilizando-se de método quantitativo, do qual visa uma análise comparativa dos dados obtidos no Sebrae, IBGE, Receita Federal e CAGED, este último vinculado ao Ministério do Trabalho. Desta forma, serão apresentados os fundamentos metodológicos, a ferramenta de pesquisa, assim como seus procedimentos, objeto estudado e o modo de acuracidade e exibição dos dados extraídos.

A próxima seção aponta o referencial teórico, tratando de temas relacionados ao empreendedorismo nas políticas públicas, ao desenvolvimento endógeno e ao Prêmio Sebrae Prefeito Empreendedor. Em seguida serão indicados os procedimentos metodológicos. Após a definição da metodologia, os resultados serão demonstrados e analisados e, finalizando o artigo, serão apresentadas as conclusões e as referências bibliográficas que nortearam as ideias aqui expostas.

\section{REFERENCIAL TEÓRICO}

\subsection{EMPREENDEDORISMO NAS POLÍTICAS PÚBLICAS}

Existem vários conceitos atribuidos ao termo empreendedorismo.De acordo com Audrestsch e Keilbach (2004), isso acontece devido a uma consequência de sua definição multidimensional. O conceito real usado para estudar ou classificar atividades empresariais reflete uma perspectiva ou ênfase particular, em que as definições de empreendedorismo geralmente variam entre o econômico e o gerenciamento das perspectivas de desenvolvimento.

Outro conceito rico sobre o termo é o exposto por Rocha e Sternberg (2005) que, posteriormente à análise teórica sobre o termo, asseguram que o empreendedorismo pode ser definido como sendo a "descoberta de oportunidades e a subsequente criação de uma nova atividade econômica, geralmente resultando na criação de novas organizações" (ROCHA; STERNBERG, 2005, p. 269).

De acordo com os conceitos obtidos dos setores da economia e da administração (MEZA, 2012), o empreendedorismo é caracterizado como inovador, inventor e criador de novas organizações e/ou atividades. Pode-se destacar, ainda, conforme o economista Joseph Alöis Schumpeter, o empreendedor "não é um cientista criando uma nova invenção, mas é quem utiliza novos meios de produção de maneira inovadora, mais vantajosa" (DROUIN, 2008, p. 140). 
Políticas públicas de empreendedorismo vislumbram propagar os indivíduos que empreendem com alto nível de inovação e que agreguem impacto significativo no desenvolvimento econômico, modificando a economia de mercado com grande potencial de valor agregado nos seguimentos de produtos e serviços (Henrekson e Stenkula, 2009).

No Brasil várias instituições, em todos os níveis de governo, estão desempenhando ações voltadas ao empreendedorismo e, concomitantemente, esferas do governo implantam políticas públicas que visam estruturar as atividades das organizações que se empenham e investem com intensidade em diversas áreas. É importante ressaltar o esforço empreendido pelo Serviço Brasileiro de Apoio às Micro e Pequenas Empresas - Sebrae, assim como o Instituto Brasileiro de Qualidade e Produtividade - IBQP que, associados a outras instituições, almejam auxiliar e propagar as ações empreendedoras no Brasil.

Esses atores desempenham as atividades em espaços e contextos que intensificam as ações entre eles, criando o ciclo de políticas públicas estruturados em fases para a caracterização de temas da ação por parte do governo, resultando em uma agenda pública. Conforme representado na Figura 1, o ciclo de políticas públicas está estruturado no processo de construção de políticas públicas.

FIgura 1 - Ciclo de Políticas Públicas
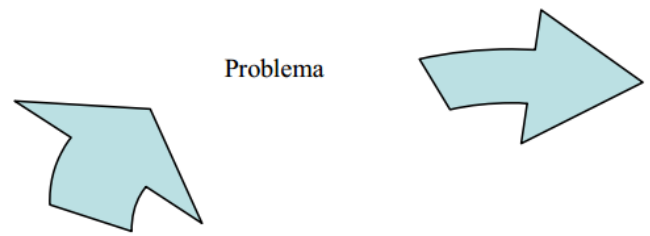

Agenda
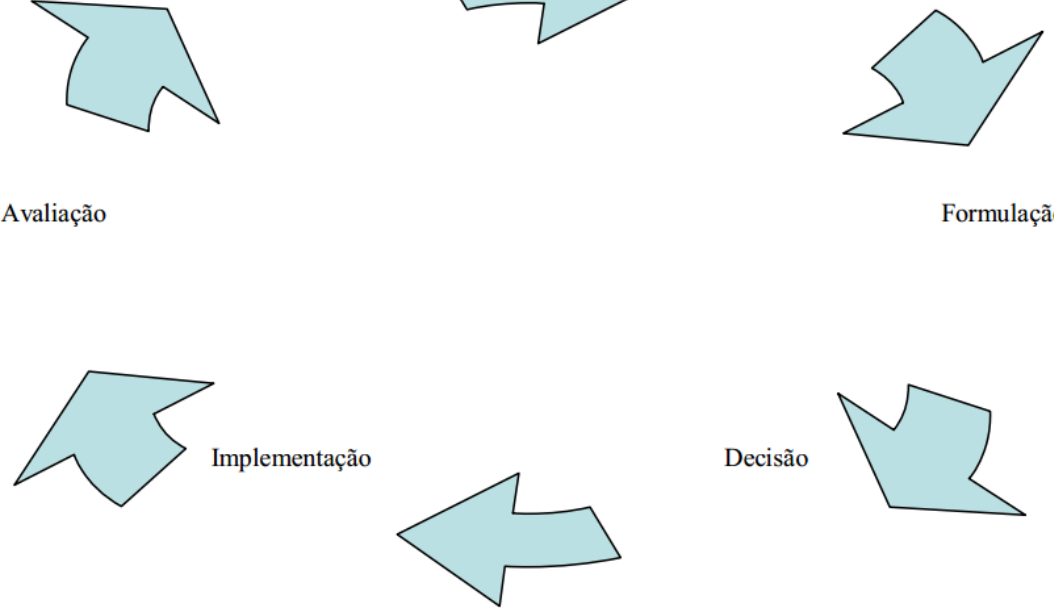

FONTE: Manual de Políticas Públicas municipais de apoio às micro e pequenas empresas

São diversas as maneiras para o incentivo ao empreendedorismo por parte dos governos. Podemos citar novamente como exemplo, o Sebrae, que criou um manual visando direcionar prefeitos empreendedores (Sebrae, 2013). Nesse manual são elencados 100 (cem) passos que auxiliam na caminhada dos prefeitos. Por obter orientações vastas, embora bem didáticas, não serão apresentadas neste trabalho.

De acordo com o Manual de Políticas Públicas Municipais de Apoio às Micro e Pequenas Empresas (Sebrae 2005, p. 15), há de se destacar a dicotomia público e privado neste contexto participativo, tendo 
em vista que são atores engajados no processo de políticas públicas que buscam o desenvolvimento do empreendedorismo.

Como modo de desenvolver e implementar políticas públicas, segue como destaque, ainda, o papel desenvolvido pelas Universidades com as incubadoras de empresas, com trabalhos desenvolvidos por empresas iniciantes, muitas dessas relacionadas a pesquisas extensionistas no âmbito universitário. É importante destacar que essas incubadoras de empresas proporcionam aos empreendedores o impulsionamento de novos negócios em diversos seguimentos, fomentando o desenvolvimento inovador de tecnologias que agregam valores nos produtos e serviços ofertados no mercado, principalmente no que se refere à sustentabilidade.

Cabe frisar que, na atualidade, as incubadoras de empresas não se prendem somente ao mercado com pilar tecnológico. Podemos citar como exemplo, especificamente no Brasil, onde já há incubadoras de empresas voltadas ao cooperativismo em diversos seguimentos, tais como: serviços, culturais e sociais. Vem motivando os indivíduos a empreenderem e desenvolverem suas atividades empreendedoras (GEM, 2007, p.169).

\subsection{DESENVOLVIMENTO ENDÓGENO}

Para Barquero (2002), num entendimento sobre o termo desenvolvimento endógeno, é como um modelo de desenvolvimento econômico eficaz. Segundo este conceito, as localidades deixam de depender do auxílio externo e passam a criar soluções internas para as dificuldades regionais. Assim, a sociedade local influencia o planejamento estratégico, que utiliza e prioriza o potencial local, trazendo o progresso aos empreendimentos e ao mercado regional, por meio do fomento e do acúmulo de recursos econômicos.

Em relação a atividade econômica, percebe-se que há um excessivo agrupamento, que imergem situações conflitantes de questionamento e oposição. Diante deste cenário, surge o conceito de desenvolvimento endógeno visando modificar este contexto. Podemos ter como definição do termo "um processo endógeno registrado em pequenas unidades territoriais e agrupamentos humanos capaz de promover o dinamismo econômico e a melhoria da qualidade de vida da população" (BUARQUE, 1999, p. 9).

Partindo das definições de (BUARQUE, 1999, p.11):

“O município tem uma escala territorial adequada à mobilização das energias sociais e integração de investimentos potencializadores do desenvolvimento, seja pelas reduzidas dimensões, seja pela aderência político-administrativa que oferece, através da municipalidade e instância governamental."

O Institut de Formation em Développement Communautaire - IFDEC (1992) sintetiza o desenvolvimento endógeno como uma intervenção tanto social quanto econômica, em que os indivíduos, ainda que este- 
jam voltadas as suas ações em um dos três setores (público, privado e social), são motivados a atuar de forma empreendedora, fomentando a utilização de recursos locais.

Pode-se dizer que o desenvolvimento endógeno é uma experiência incipiente em território brasileiro, e que as ações dentro deste contexto não atingiam o grau desejado de eficácia, sendo direcionadas de modo desastroso nas últimas décadas. A motivação às ações empreendedoras são inseridas neste cenário e possibilitam caminhos para que os municípios propaguem o desenvolvimento endógeno, além de ser considerada uma iniciativa importante a ser adotada como uma política pública pelos municípios.

Os municípios, por meio de direitos concedidos pela Constituição de 1988, tiveram a prerrogativa de elaborar seus próprios regulamentos locais. Instituída pelo nome de Lei Orgânica Municipal, que propiciou diversos ajustes legais no âmbito do governo brasileiro. Para Frey (2000, p. 243), embora haja uma associação entre os poderes Legislativo e Executivo no nível do governo municipal e não mostrar diferenças significativas de uma localidade para outra, desta forma, há uma "pluralidade institucional", onde se torna difícil o desenvolvimento de políticas públicas em nível municipal.

A Constituição de 1988 com sua proclamação redirecionou a função dos municípios. Trata-se de um período intitulado como "a grande encruzilhada" (vAZ; CALDAS, 2006 apud MARTINS et al., 2010). Isto ocorreu devido à crescente arrecadação própria de tributos pelos municípios, associada a novas responsabilidades e obrigações. Os municípios passaram a ter o compromisso com as ações voltadas ao bem-estar social que antes competiam aos níveis do governo federal ou aos governos estaduais. Ademais tiveram que se ver obrigados a fomentar o desenvolvimento na economia local (ABRUCiO; coUTO, 1996). As pressões e reivindicações por atendimento às demandas comedidas de infraestrutura urbana e serviços públicos básicos, assim como políticas sociais, consumiam a maior parte da energia dos governantes municipais e dos recursos disponíveis nos municípios (MARTINs et al., 2006, p. 3).

É importante destacar que Canever et al. (2010) ressaltam a falta de estudos nesta área, principalmente no que se refere a pesquisas sobre os impactos das ações empreendedoras no desenvolvimento endógeno, justamente pelas restrições sobre conceitos e metodologias, entretanto, percebe-se que este cenário tem se modificado, principalmente pelo fato da incorporação do empreendedorismo como um instrumento fundamental na elaboração de políticas públicas.

\subsection{PRÊMIO SEBRAE PREFEITO EMPREENDEDOR}

O Sebrae é bem conhecido também pelas premiações concedidas e como instrumento de motivação no mercado brasileiro. O Prêmio Sebrae Prefeito Empreendedor é uma premiação oferecida pelos bons serviços ofertados à sociedade, sendo considerado uma boa maneira de fomentar ações empreendedoras em vários seguimentos. 
É importante destacar que o objetivo fundamental do Sebrae é ajudar na implantação e no desenvolvimento de pequenas empresas. Contudo, para que isso aconteça, é essencial que o governo participe , a fim de que possa auxiliar o Sebrae a disponibiliza projetos peculiares para inspirar os governantes sobre a necessidade de fomentar o empreendedorismo nos municípios.

O Sebrae criou a premiação em 2001, abrangendo todas as regiões do Brasil. A cada 2 (dois) anos prefeitos que se sobressaem por implementar práticas inovadoras de inclusão na produção local, proporcionando oportunidades de inserção do cidadão no mercado de trabalho, com padrão de qualidade e equidade na distribuição de renda, serão agraciados com o prêmio.

O Sebrae condecora os prefeitos que alcançam este objetivo, conferindo-lhes o valoroso Prêmio Prefeito Empreendedor. O objetivo central deste prêmio é mostrar e agraciar as principais ações empreendedoras de inserção produtiva de políticas públicas no Brasil, tornando-os como bons exemplos para impulsionar outros prefeitos e demais atores regionais a examinarem as ações desenvolvidas e moldá-las, de acordo com o contexto de seu município, possibilitando o fortalecimento local às micro e pequenas empresas. Ademais, a referida instituição elabora constantemente orientações como manuais e guias acerca do assunto, visando auxiliar prefeitos e possíveis empreendedores que buscam a trajetória do desenvolvimento.

Seguindo os critérios do Prêmio Sebrae Prefeito Empreendedor, o regulamento é separado da seguinte forma (Sebrae, 2018):

“[...] é dividido nas etapas estadual e nacional. Na etapa estadual, são selecionados os vencedores estaduais ou distritais para cada uma das categorias e, na etapa nacional, são selecionados sete vencedores nacionais das categorias temáticas e cinco vencedores regionais da categoria "Políticas Públicas para o Desenvolvimento dos Pequenos Negócios".

As etapas estadual e nacional do Prêmio Sebrae Prefeito Empreendedor, em geral, são divididas em oito categorias para premiação, a saber (Sebrae, 2018):

- Políticas Públicas para o Desenvolvimento dos Pequenos Negócios;

- Cooperação Intermunicipal para o Desenvolvimento Econômico;

- Compras Governamentais de Pequenos Negócios;

- Pequenos Negócios no Campo;

- Inovação e Sustentabilidade;

- Empreendedorismo nas Escolas;

- Desburocratização e Implementação da Rede Simples;

- Inclusão Produtiva e Apoio ao Microempreendedor Individual (MEI). 
Ainda de acordo com o regulamento do (Sebrae, 2018), "os projetos que concorrem ao Prêmio Sebrae Prefeito Empreendedor devem ter os Pequenos Negócios como seu público alvo e foco das ações municipais".

São consideradas empresas formais de Pequenos Negócios as que se enquadram nas características previstas na (Lei Complementar 123/2016), sintetizadas da seguinte maneira:

- Microempreendedor Individual (MEI) é empresário individual com faturamento anual até $\mathrm{R}$ \$60.00o,oo (até dez/2017) ou até $\mathrm{R} \$$ 81.000,00 (a partir de jan/2018);

- Microempresa (ME) é a empresa com faturamento anual até R\$ 360.000,00 (sem alteração do teto em 2018);

- Empresa de Pequeno Porte (EPP) é a empresa com faturamento anual até $\mathrm{R} \$$ 3.600.000,00 (até dez/2017) ou até $\mathrm{R} \$$ 4.800.000,00 (a partir de jan/2018);

- Agricultor Familiar é aquele que pratica as atividades no meio rural e que atenda os requisitos da Lei 11.326/2006 e que seja detentor da DAP (Declaração de Aptidão ao PRONAF);

- Produtor Rural Pessoa Física é a pessoa que explora atividade agrícola e/ou pecuária nas quais não sejam alteradas a composição e as características dos produtos "in natura" e que faturem o valor de até $\mathrm{R} \$$ 3.600.000,00 (três milhões e seiscentos mil reais) anual e possuam inscrição estadual de produtor, somando a esse grupo os pescadores com registro geral da pesca;

- Empreendimento Econômico Solidário é aquele definido pelo Decreto 7.358/2010 e mencionado na RDC 49/2013 da ANVISA;

- Empresa em Processo de Formalização é aquela que já iniciou os procedimentos para sua regularização perante os órgãos públicos".

\section{METODOLOGIA}

\subsection{FUNDAMENTOS METODOLÓGICOS}

No que se refere aos fundamentos metodológicos, observa-se ser uma pesquisa científica, que se inicia com um levantamento das informações, podendo ser elaborados pelas seguintes formas: pesquisa documental, cujas fontes são primárias ou bibliográfica, cujas fontes são secundárias. A pesquisa documental é muito usada nos estudos das ciências sociais e há características parecidas com a pesquisa bibliográfica. Entretanto no que se refere à natureza das fontes de informações, há diferença entre as duas. Os termos pesquisa documental e pesquisa bibliográfica no entendimento das autoras Marconi e Lakatos (2011, p. 43-44), pesquisa documental envolve "todos os materiais, ainda não elaborados, escritos ou não, que podem servir como fonte de informação 
para a pesquisa científica (MARCONI; LAKATOS, 2011, p. 43)"; e a pesquisa bibliográfica "refere-se ao levantamento de toda a bibliografia já publicada em forma de livros, revistas, publicações avulsas e imprensa escrita. Sua finalidade é colocar o pesquisador em contato direto com tudo aquilo que foi escrito sobre determinado assunto [...] (MARCONI; LAKATOS, 2011, p. 43-44)".

Neste contexto metodológico, este trabalho considera esta pesquisa como documental, uma vez que utiliza como fonte principal os dados obtidos pelas entidades Sebrae, IBGE, Receita Federal e CAGED, sem que houvesse sido usada anteriormente. Conquanto a de valer-se ainda da bibliografia pertinente ao tema abordado, nas fundamentações, na descrição do contexto dos objetivos e principalmente na revisão da literatura.

No que se refere à característica descritiva deste artigo, Demo (2012, p. 11), utiliza em sua definição de pesquisa o sentido desse modo de expor uma realidade, ao afirmar que "Alguns entendem por pesquisa o trabalho de coletar dados, sistematizá-los e, a partir daí fazer uma descrição da realidade".

A análise dos dados, assim como a sua interpretação, no que se refere à pesquisa documental, se diferencia conforme a natureza dos documentos usados. Para as pesquisas que usam dados quantitativos, representados por banco de dados ou tabelas, assim como são as informações obtidas pelo Sebrae, IBGE, Receita Federal e CAGED, todo procedimento detalhado de modo geral abrange métodos estatísticos. (GIL, 2010, p.67).

Aconselha-se aos pesquisadores serem mais cautelosos no que se refere à utilização de fontes de dados estatísticas:

"[...] encontrar a definição exata da unidade coletada e generalizada; verificar a homogeneidade do elemento generalizado; verificar a homogeneidade da relação entre a quantidade medida mediante o total e seus diversos elementos, assim como a quantidade que interessa ao investigador; saber com referência a que devemos calcular as percentagens." (GRAWITZ apud MARCONI; LAKATOS, 2011, p. 53)

De forma efetiva, pretende-se sujeitar os dados obtidos do Sebrae, IBGE, Receita Federal e CAGED a apurações estatísticas, de modo a alcançar os objetivos apresentados, contudo, para o alcance do sucesso de um processo de análise é fundamental que o pesquisador trabalhe de forma integrada com dados qualitativos e quantitativos disponíveis, realizando uma análise comparativa dos resultados obtidos, de modo a causar no pesquisador a formação de definições qualitativas que agreguem valor. Os dados quantitativos, resultantes de levantamentos estatísticos, ao serem utilizados de forma agregada e complementar aos múltiplos ângulos das informações qualitativas podem possibilitar análises e avaliações mais consistentes e significativas. (BELLONI; MAGALHÃES; SOUZA, 2007). 


\subsection{FERRAMENTA DE PESOUISA}

A ferramenta de pesquisa usada neste trabalho foi essencial para extrair, unir e organizar as informações da base de dados do Sebrae, IBGE, Receita Federal e CAGED. Utilizando-se, para melhor elucidar nas fases de unir e organizar os dados obtidos, assim como na apresentação dos resultados foi utilizada a ferramenta necessária na criação de tabelas, por intermédio do Microsoft Excel.

\subsection{PROCEDIMENTOS DE PESOUISA}

Os procedimentos para a execução da pesquisa são descritos da seguinte forma:

Download dos dados - Os dados do Sebrae, IBGE, Receita Federal e CAGED são acessíveis ao público, sendo baixados pelos sites das respectivas entidades. Os dados estão disponibilizados por ano, possibilitando ao pesquisador uma melhor observação evolutiva dos dados atuais ou histórico.

Seleção dos dados - Depende dos dados que se pretende obter na pesquisa realizada, permitindo uma seleção de entradas fundamentada em diversos padrões, até mesmo em variáveis próprias. Além disso, possibilita, ainda, empregar métodos lógicos, sozinhos ou agrupados, que mantenham a saída das informações a um composto específico de características.

Análises dos dados - permite aprofundar a análise sobre diversos dados, investigar variáveis acerca da estruturação das informações obtidas, identificar discrepâncias e anormalidades, e por fim analisar as interações entre as variáveis usadas.

\subsection{OBJETO DE PESQUISA}

No que se refere ao objeto de pesquisa, foram considerados os municípios alagoanos ganhadores do Prêmio Prefeito Empreendedor do Sebrae edição número VIII (2014); as características demográficas destes municípios; os saldos dos empregos formais nos municípios vencedores do prêmio Prefeito Empreendedor entre os anos de 2012 a 2017; as variações anuais dos empregos; os valores do PIB per capita dos municípios vencedores do prêmio e do estado de Alagoas, assim como do estado de Alagoas e estado de Alagoas sem os dados dos municípios vencedores; e por fim o quantitativo do Simples Nacional obtido no site da receita federal no período de 2012-2017.

\subsection{ACURACIDADE E EXIBIÇÃO DOS DADOS}

A acuracidade e exibição dos dados fazem parte da fase de cálculo da quantidade de municípios vencedores do Prêmio Sebrae Prefeito Empreendedor no estado de Alagoas, levando em consideração aspec- 
tos como a população, área demográfica, número de empregos ou PIB per capita, apresentando os resultados, compreendidos no período de 06 (cinco) anos pesquisados, foram necessárias informações de cada ano (2012 a 2017).

A forma como os dados serão apresentados ajudará na análise comparativa no que se refere aos indicadores do estado de Alagoas, desta forma, optou-se por utilizar tabelas e figuras para melhor elucidação da análise comparativa da apresentação dos dados, considerando os indicadores extraídos e calculados, dos quais serão as quantidades das variáveis das amplitudes que essas representam.

\section{RESULTADOS E ANÁLISES}

Na Tabela 1, são mostrados os municípios alagoanos ganhadores do Prêmio Prefeito Empreendedor do Sebrae edição número VIII (2014). Os vencedores são mostrados de acordo com a categoria vencida e com o nome do projeto ganhador.

TABela 01 - Municípios Alagoanos vencedores do Prémio Prefeito Empreendedor Edição VIII

\begin{tabular}{|c|c|c|}
\hline CATEGORIA & VENCEDOR & NOME DO PROJETO \\
\hline $\begin{array}{l}\text { Compras } \\
\text { Governamentais }\end{array}$ & Mar Vermelho & $\begin{array}{c}\text { Associação Das Costureiras Mar } \\
\text { Vermelho: Transformando Arte } \\
\text { Em Renda }\end{array}$ \\
\hline Lei Geral & Teotônio Vilela & Desenvolvimento Sustentável \\
\hline $\begin{array}{l}\text { Melhor Projeto } \\
\text { Região Nordeste }\end{array}$ & $\begin{array}{l}\text { Santanta Do } \\
\text { Ipanema }\end{array}$ & Santana Mais Empreendedora \\
\hline Desburocratização & Messias & $\begin{array}{l}\text { Unidos Por Messias } \\
\text { Empreendedora }\end{array}$ \\
\hline $\begin{array}{l}\text { Pequenos Negócios } \\
\text { No Campo }\end{array}$ & Arapiraca & Mulheres Empreendedoras \\
\hline Novos Projetos & Capela & $\begin{array}{c}\text { Projeto Farinheiro - Cultura E } \\
\text { Empreendedorismo }\end{array}$ \\
\hline
\end{tabular}

FONTE: Sebrae.

Analisando os projetos vencedores, observa-se que todos têm seus objetivos voltados para o fomento do empreendedorismo local.

$\mathrm{Na}$ Tabela 2, são mostradas as características demográficas no ano que foi realizado o prêmio e no ano de 2017 , assim como a área territorial dos municípios ganhadores. 
TABela 02 - Características Demográficas e Territorial dos municípios vencedores do prêmio

\begin{tabular}{c|c|c|c}
$\begin{array}{c}\text { MUNICÍPIOS } \\
\text { VENCEDORES }\end{array}$ & $\begin{array}{c}\text { POPULAÇÃO } \\
2014\end{array}$ & $\begin{array}{c}\text { POPULAÇÃO } \\
2017\end{array}$ & ÁREA KM $^{2}$ \\
\hline Mar Vermelho & 3.674 & 3.579 & 92 \\
\hline $\begin{array}{c}\text { Teotônio Vilela } \\
\text { Santanta do } \\
\text { Ipanema }\end{array}$ & 43.895 & 44.666 & 300 \\
\hline Messias & 17.350 & 17.988 & 115 \\
\hline Arapiraca & 229.329 & 234.185 & 345 \\
\hline Capela & 17.591 & 17.354 & 257
\end{tabular}

Fonte: IBGE (Instituto Brasileiro de Geografia e Estatística).

Analisando o dado da tabela é possível constatar a grande diversidade dos munícipios ganhadores do prêmio em relação à área territorial e à sua população, com municípios com cerca de 3.600 habitantes e $92 \mathrm{~km}^{2}$ de área como Mar Vermelho, contrastando com municípios como Arapiraca com cerca de 235.00o habitantes e Santana do Ipanema com uma área de quase $44 \mathrm{oKm}^{2}$. Estas características indicam, que o prêmios é bem heterogêneo em relação aos aspectos observados.

Na Tabela 3 são mostrados os dados do saldo dos empregos formais nos municípios vencedores do prêmio Prefeito Empreendedor entre os anos de 2012 a 2017. Os dados foram obtidos através das estatísticas do CAGED (Cadastro Geral dos Empregados e Desempregados), que apresenta a quantidade de empregados sob regime celetista, trabalhadores regidos pelo Estatuto do Trabalhador Rural, aprendizes e trabalhadores temporários. Para fins de comparação são mostrados os dados do estado de Alagoas e do estado de Alagoas com a exclusão dos dados dos municípios vencedores do prêmio. Para melhor análise dos resultados, na Tabela 4 são mostradas as variações anuais dos empregos.

TABELA 03 - Saldo empregos dados CAGED

\begin{tabular}{c|c|c|c|c|c|c} 
MUNICÍpIOS & 2012 & 2013 & 2014 & 2015 & 2016 & 2017 \\
Mar Vermelho & 7 & -3 & 1 & 1 & 0 & 4 \\
\hline Teotônio Vilela & 216 & 336 & -940 & -253 & -416 & -258 \\
\hline $\begin{array}{c}\text { Santanta do } \\
\text { Ipanema }\end{array}$ & 129 & 658 & 259 & 46 & 90 & -109 \\
\hline Messias & 35 & -9 & 134 & -25 & -76 & 53 \\
\hline Arapiraca & 2075 & 1695 & 1083 & 2080 & 18 & -273 \\
\hline Capela & 27 & 14 & 27 & -81 & -7 & -57 \\
\hline Alagoas & 3.307 & -628 & -2.362 & -4.303 & -11.559 & -8.255 \\
\hline $\begin{array}{c}\text { Alagoas sem } \\
\text { os municípios } \\
\text { ganhadores }\end{array}$ & 818 & -3.319 & -2.926 & -6.071 & -11.168 & -7.615
\end{tabular}

FONTE: Ministério do Trabalho. 
TABELA 04 - Variação Anual empregos dados CAGED

\begin{tabular}{c|c|c|c|c|c}
\hline \multicolumn{7}{c}{ VARIAÇÃO ANUAL EMPREGOS FORMAIS CAGED } \\
\hline MUNICÍPIOS & $\begin{array}{c}\text { VARIAÇÃO } \\
\text { ANUAL } \\
2012-2013\end{array}$ & $\begin{array}{c}\text { VARIAÇÃO } \\
\text { ANUAL } \\
2013-2014\end{array}$ & $\begin{array}{c}\text { VARIAÇÃO } \\
\text { ANUAL } \\
2014-2015\end{array}$ & $\begin{array}{c}\text { VARIAÇÃO } \\
\text { ANUAL } \\
2015-2016\end{array}$ & $\begin{array}{c}\text { VARIAÇÃO } \\
\text { ANUAL } \\
2016-2017\end{array}$ \\
\hline Mar Vermelho & $-142,86 \%$ & $-133 \%$ & $0,00 \%$ & $-100,00 \%$ & - \\
\hline Teotônio Vilela & $55,56 \%$ & $-380 \%$ & $-73,09 \%$ & $64,43 \%$ & $-38 \%$ \\
\hline $\begin{array}{c}\text { Santanta do } \\
\text { Ipanema }\end{array}$ & $410,08 \%$ & $-61 \%$ & $-82,24 \%$ & $95,65 \%$ & $-221 \%$ \\
\hline Messias & $-125,71 \%$ & $-1589 \%$ & $-118,66 \%$ & $204,00 \%$ & $-170 \%$ \\
\hline Arapiraca & $-18,31 \%$ & $-36 \%$ & $92,06 \%$ & $-99,13 \%$ & $-1617 \%$ \\
\hline Capela & $-48,15 \%$ & $93 \%$ & $-400,00 \%$ & $-91,36 \%$ & $714 \%$ \\
\hline Alagoas & $-118,99 \%$ & $276 \%$ & $82,18 \%$ & $168,63 \%$ & $-29 \%$ \\
\hline $\begin{array}{c}\text { Alagoas sem } \\
\text { os municípios } \\
\text { ganhadores }\end{array}$ & $-505,75 \%$ & $-12 \%$ & $107,48 \%$ & $83,96 \%$ & $-32 \%$ \\
\hline
\end{tabular}

FONTE: Ministério do Trabalho.

Observando os dados da Tabela 3, observa-se que nos dois primeiros anos (2012-2013), período principal em que foram analisados os projetos do prêmio, os resultados do estado de Alagoas diminuem drasticamente com a exclusão dos dados dos municípios ganhadores do prêmio, com destaque para o impacto da cidade de Arapiraca. Esta informação é corroborada com os resultados da Tabela 4, onde observa-se que a variação do estado de Alagoas entre 2012-2013 é cerca de 6 vezes menor, quando retirados os dados das cidades premiadas. Entretanto, nos anos seguintes é observado uma diminuição da influência positiva dos resultados dos municípios premiados em relação ao estado de Alagoas, com os valores tanto absolutos, quanto de percentual de variação, oscilando ao longo dos anos, sem nenhuma interpretação de tendências positivas ou negativas relevantes dos municípios premiados.

Na Tabela 5, são mostrados os valores do PIB per capita dos municípios vencedores do prêmio e do estado de Alagoas, assim como do estado de Alagoas e estado de Alagoas sem os dados dos municípios vencedores. Os dados foram obtidos no IBGE, cujas informações disponíveis abrangem até o ano de 2015. Para auxiliar na avaliação dos resultados, na Tabela 6 são mostradas as variações anuais dos valores dos PIB per capita, mostrados na Tabela 5. 
TABELA 05 - Evolução do PIB per capita dos munícipios vencedores e estado de Alagoas

\begin{tabular}{c|c|c|c|c}
\multirow{2}{*}{ MUNICÍPIOS } & 2012 & 2013 & 2014 & 2015 \\
\cline { 2 - 5 } & $\begin{array}{c}\text { PIB PER } \\
\text { CAPITA }\end{array}$ & $\begin{array}{c}\text { PIB PER } \\
\text { CAPITA }\end{array}$ & $\begin{array}{c}\text { PIB PER } \\
\text { CAPITA }\end{array}$ & $\begin{array}{c}\text { PIB PER } \\
\text { CAPITA }\end{array}$ \\
\hline Mar Vermelho & 6.038 & 6.631 & 6.920 & 7.701 \\
\hline $\begin{array}{c}\text { Teotônio Vilela } \\
\text { Santanta do } \\
\text { Ipanema }\end{array}$ & 7.397 & 7.839 & 7.057 & 8.945 \\
\hline Messias & 5.782 & 7.016 & 8.206 & 8.382 \\
\hline Arapiraca & 12.786 & 13.063 & 14.986 & 16.960 \\
\hline Capela & 7.513 & 8.501 & 8.371 & 9.020 \\
\hline Alagoas & 10.946 & 11.295 & 12.717 & 13.878 \\
\hline $\begin{array}{c}\text { Alagoas sem } \\
\text { os municípios } \\
\text { ganhadores }\end{array}$ & 10.971 & 11.314 & 12.751 & 13.842 \\
\hline
\end{tabular}

FONTE: IBGE (Instituto Brasileiro de Geografia e Estatística).

TABELA 06 - Evolução da variação do PIB per capita dos munícipios vencedores e estado de Alagoas.

\begin{tabular}{c|c|c|c}
\multicolumn{5}{c}{ VARIAÇÃO ANUAL PIB PER CAPITA } \\
\hline MUNICíPIOS & $\begin{array}{c}\text { VARIAÇÃO ANUAL } \\
2012-2013\end{array}$ & $\begin{array}{c}\text { VARIAÇÃO ANUAL } \\
2013-2014\end{array}$ & $\begin{array}{c}\text { VARIAÇÃO ANUAL } \\
2014-2015\end{array}$ \\
\hline Mar Vermelho & $9,83 \%$ & $4 \%$ & $11,29 \%$ \\
\hline Teotônio Vilela & $5,97 \%$ & $-10 \%$ & $26,76 \%$ \\
\hline Santanta do Ipanema & $4,84 \%$ & $12,25 \%$ & $15,20 \%$ \\
\hline Messias & $21,34 \%$ & $17 \%$ & $2,15 \%$ \\
\hline Arapiraca & $2,17 \%$ & $15 \%$ & $13,18 \%$ \\
\hline Capela & $13,15 \%$ & $-2 \%$ & $7,76 \%$ \\
\hline Alagoas & $3,18 \%$ & $12,59 \%$ & $9,13 \%$ \\
\hline $\begin{array}{c}\text { Alagoas sem os } \\
\text { municípios ganhadores }\end{array}$ & $3,12 \%$ & $12,70 \%$ & $8,56 \%$
\end{tabular}

Fonte: IBGE (Instituto Brasileiro de Geografia e Estatística).

Avaliando os resultados da Tabela 6 observa-se que houve baixa oscilação dos resultados da variação do PIB per capita, quando ocorre a comparação do estado de Alagoas sem os municípios vencedores, com os dados com os municípios vencedores. Entretanto, quando se observa os municípios individualmente no período de 2012-2013, que foi o intervalo de tempo analisado para a premiação, cinco do seis municipais ganhadores tiveram médias maiores que a do estado de Alagoas.

Na Tabela 7, são mostrados o quantitativo do Simples Nacional obtido no site da receita federal no período de 2012-2017, que abrange o quantitativo dos microempreendedores individuais empresa de pequeno porte, e microempresas. Na Tabela 8 são mostradas as variações anuais que ocorreram no período. 
TABELA 07 - Estatística do Simples Nacional (inclusive com MEI).

\begin{tabular}{c|c|c|c|c|c|c}
\multicolumn{8}{c}{ ESTATÍSTICA DO SIMPLES NACIONAL - (INCLUSIVE COM MEI) } \\
\hline MUNICÍPIOS & 2012 & 2013 & 2014 & 2015 & 2016 & 2017 \\
\hline Mar Vermelho & 36 & 64 & 68 & 82 & 86 & 90 \\
\hline $\begin{array}{c}\text { Teotônio Vilela } \\
\text { Santanta do } \\
\text { Ipanema }\end{array}$ & 897 & 1039 & 1165 & 1198 & 1250 & 1300 \\
\hline Messias & 347 & 397 & 452 & 500 & 530 & 546 \\
\hline Arapiraca & 7731 & 8832 & 9461 & 9991 & 10205 & 9662 \\
\hline Capela & 398 & 483 & 560 & 584 & 592 & 622 \\
\hline Alagoas & 73379 & 86275 & 98715 & 108557 & 115253 & 123454 \\
\hline $\begin{array}{c}\text { Alagoas sem } \\
\text { os municípios } \\
\text { ganhadores }\end{array}$ & 62978 & 74334 & 85760 & 94860 & 101154 & 109730 \\
\hline
\end{tabular}

FONTE: Receita Federal.

TABELA 08 - Variação anual da Estatística do simples Nacional

\begin{tabular}{c|c|c|c|c|c}
\multicolumn{7}{c}{ VARIAÇÃO ANUAL SIMPLES NACIONAL } \\
\hline MUNICíPIOS & $2012-2013$ & $2013-2014$ & $2014-2015$ & $2015-2016$ & $2016-2017$ \\
\hline Mar Vermelho & $77,78 \%$ & $6,25 \%$ & $20,59 \%$ & $4,88 \%$ & $4,65 \%$ \\
\hline Teotônio Vilela & $15,83 \%$ & $12,13 \%$ & $2,83 \%$ & $4,34 \%$ & $4,00 \%$ \\
\hline $\begin{array}{c}\text { Santanta do } \\
\text { Ipanema }\end{array}$ & $13,51 \%$ & $10,92 \%$ & $7,45 \%$ & $7,00 \%$ & $4,74 \%$ \\
\hline Messias & $14,41 \%$ & $13,85 \%$ & $10,62 \%$ & $6,00 \%$ & $3,02 \%$ \\
\hline Arapiraca & $14,24 \%$ & $7,12 \%$ & $5,60 \%$ & $2,14 \%$ & $-5,32 \%$ \\
\hline Capela & $21,36 \%$ & $15,94 \%$ & $4,29 \%$ & $1,37 \%$ & $5,07 \%$ \\
\hline Alagoas & $17,57 \%$ & $14,42 \%$ & $9,97 \%$ & $6,17 \%$ & $7,12 \%$ \\
\hline $\begin{array}{c}\text { Alagoas sem } \\
\text { os municípios } \\
\text { ganhadores }\end{array}$ & $18,03 \%$ & $15,37 \%$ & $10,61 \%$ & $6,64 \%$ & $8,48 \%$ \\
\hline
\end{tabular}

FONTE: Receita Federal. FONTE: Receita Federal.

Avaliando os dados da Tabela 8, observa-se que no período observado os valores das variações anuais de adesão ao Simples Nacional do estado de Alagoas em comparação com o estado de Alagoas sem os dados dos municípios ganhadores do prêmio do Sebrae, ficaram muito próximas, com diferenças menores que 1\%. Em relação aos dados dos municípios observar-se novamente que no período de 2012-2013, que foi o período de implantação dos projetos ganhadores, os municípios tiveram suas maiores variações positivas, indicando que as políticas implantadas no período foram bastante efetivas. 


\section{CONCLUSÃO}

O objetivo deste trabalho foi avaliar se os municípios vencedores do Prêmio Sebrae Prefeito Empreendedor no estado de Alagoas, apresentariam melhores resultados em indicadores que estão relacionados com políticas públicas de fomento ao empreendedorismo e ao desenvolvimento endógeno. Para isto avaliou os resultados dos municípios ao longo de um período antes e posterior à premiação e utilizou os resultados do estado de Alagoas, como critério da comparação.

Analisando a diversidade dos municípios vencedores do prêmio Prefeito Empreendedor do Sebrae, observa-se que os critérios de julgamento dos projetos são técnicos, não levando em consideração aspectos como a população, área demográfica, número de empregos ou PIB per capita.

Os resultados dos números de empregos de acordo com a estatística do CAGED, mostraram que principalmente no período de 20122013, ano de avaliação dos projetos, os municípios vencedores tiveram resultados muito superiores que os do estado de Alagoas, isto é verificado, quando a variação do emprego do estado de Alagoas sem os dados dos municípios vencedores, é cerca de 6 vezes menor, que os dados com a inclusão dos dados dos premiados pelo Sebrae. Nos demais anos, observa-se que os resultados das cidades não causaram grande diferenças no resultado estadual, pois as diferenças não apresentaram grandes variações. Entretanto, avaliando os municípios isolados, observa-se que a partir de 2014, cerca de $67 \%$ dos resultados tiveram variações negativas. Apesar, de não ser o objetivo do trabalho, uma possível explicação para esta situação seria a crise econômica que assolou o Brasil no período em questão, que podem ter potencializado efeitos negativos em cidades que busquem o desenvolvimento endógeno.

Os resultados do PIB per capita, corroboram com um melhor desempenho dos municípios no período de 2012-2013, com os valores da variação do PIB per capita de 5 dos 6 municípios premiados, superiores à média estadual. Nos demais períodos, observa-se que os resultados oscilaram e ficaram próximos a média estadual. Em relação a comparação dos dados do estado de Alagoas com e sem os municípios vencedores, é constatado pouca diferença, pois com exceção da cidade de Arapiraca, as demais cidades não têm grande peso na composição dos resultados estaduais.

O indicador de participantes do Simples Nacional das cidades premiadas, que incluem microempreendedores individuais, microempresas e empresas de pequeno porte, apresentaram de maneira geral os resultados próximos às médias estaduais durante os períodos estudados. Porém, novamente nos anos de 2012 e 2013, foi o período em que os municípios tiveram as suas maiores variações positivas.

Portanto, os resultados indicam que principalmente no intervalo de tempo de 2012-2013, período de avaliação do prêmio, os municípios premiados tiveram em sua grande maioria resultados elevados tanto 
em relação aos períodos posteriores, quanto em relação aos dados estaduais. Entretanto, nos períodos posteriores, os resultados acompanharam os valores das médias do estado de Alagoas, ocorrendo pequenas variações. Desse modo, pode-se concluir que o prêmio Sebrae, gerou um impacto positivo e constitui um indicador de que os municípios aplicavam políticas públicas de desenvolvimento endógeno, além de gerar um excelente banco de dados para projetos na área de desenvolvimento endógenos. Entretanto, deve-se avaliar todo a conjectura local e macroeconômica para estudar porque nos anos seguintes, os resultados não foram tão significativos.

Por fim, como sugestões de trabalhos futuros podem-se citar: realizar o estudo em outros estados, analisar os impactos dos projetos desenvolvidos em um determinado município e avaliar as causas que motivaram os resultados obtidos neste estudo.

\section{REFERÊNCIAS BIBLIOGRÁFICAS}

ABRUCIO, F. L.; COUTO, C. G. A redefinição do papel do Estado no âmbito local. São Paulo perspect, v. 10, n. 3, p. 40-47, jul./set. 1996. Disponível em: $<$ http://produtos.seade.gov.br/produtos/spp/index. php?men $=$ rev\&cod=5035 $>$. Acesso em: 10 de fevereiro de 2018.

AUDRETSCH, D.; KEILBACH, M. Entrepreneurship Capital and Economic Performance. ZEW Discussion Papers 02-76, ZEW - Zentrum für Europäische Wirtschaftsforschung / Center for European Economic Research, 2002. Disponível em: $<\mathrm{ftp}$ ://ftp.zew. de/pub/zewdocs/dp/dpo276.pdf>. Acesso em: 29 de janeiro de 2018.

BARQUERO, Antonio Vásquez. Desenvolvimento endógeno em tempos de globalização. Tradução: Ricardo Brinco. Porto Alegre: Fundação de Economia e Estatística, 2002. 28op.

BELLONI, Isaura; MAGALHÃES, Heitor de; SOUSA, Luzia Costa de. Metodologia de avaliação em políticas públicas: uma experiência em educação profissional. Editora Cortez, 2007.

BRASIL. Lei Complementar nº 123, de 14 de dezembro de 2006. Institui o Estatuto Nacional da Microempresa e da Empresa de Pequeno Porte. Disponível em: < http://www.planalto.gov.br/ CCivil_03/leis/LCP/Lcp123.htm>. Acesso em: 16 de fevereiro de 2018.

BRASIL. Lei Complementar nำ 127, de 14 de agosto de 2007. Altera o Estatuto Nacional da Microempresa e da Empresa de Pequeno Porte. Disponível em: <http://www.planalto.gov.br/ ccivil_03/leis/lcp/lcp127.htm>. Acesso em: 16 de fevereiro de 2018.

BUARQUE, S. C. Metodologia de planejamento do desenvolvimento local e municipal sustentável. Material para orientação técnica e treinamento de multiplicadores e técnicos em planejamento local e municipal. Brasília, junho de 1999. 
CANEVER, M. D. et al. Entrepreneurship in the Rio Grande do Sul, Brazil: the determinants and consequences for the municipal development. Econ. Sociol. Rural, Brasília, v. 48, n. 1, mar. 2010. Disponível em: <http://www.scielo.br/scielo. php?script=sci_arttext\&pid=S0103-20032010000100005\&ln $\mathrm{g}=\mathrm{en} \& \mathrm{nrm}=\mathrm{iso}>$. Acesso em: 10 de fevereiro de 2018.

DEMO, Pedro. Pesquisa e construção do conhecimento: metodologia científica no caminho de Habermas. Rio de Janeiro: Editora Tempo Brasileiro, 1994.

Pedro. Metodologia científica em ciências sociais. $3^{\underline{a}}$ edição. São Paulo: Editora Atlas, 2012.

DROUIN, J. Os Grandes Economistas. São Paulo: M. Fontes, 2008.

Empreendedorismo no Brasil: 2006 (Global Entrepreneurship Monitor 2006 - GEM 2006).-Curitiba : IBQP, 2007.

FREY, Klaus. Políticas públicas: um debate conceitual e reflexões referentes à prática da análise de políticas públicas no Brasil. Planejamento e Políticas Públicas, Brasília, n. 21, p. 211-259, jun. 2000.

GIL, Antônio Carlos. Como elaborar projetos de pesquisa. 5a edição. São Paulo: Editora Atlas, 2010.

HENREKSON, M., STENKULA, M., Entrepreneurship and public policy, IFN Working Paper No. 804, 2009.

IFDEC - Institut de Formation em Développement Communautaire. Le développement économique communautaire et les CDEC montréalaises. Colloque d'orientation, Montréal, 1992.

MARCONI, Marina de Andrade; LAKATOS, Eva Maria. Metodologia do trabalho científico: procedimentos básicos, pesquisa bibliográfica, projeto e relatório, publicações e trabalhos científicos. 7. ed. - 6. reimpr. São Paulo: Atlas: 2011.

MARTINS, R. D; VAZ, J. C.; CALDAS, E. L. A gestão do desenvolvimento local no Brasil: (des)articulação de atores, instrumentos e território. Adm. Pública, Rio de Janeiro, v. 44, n. 3, jun. 2010. Disponível em: <http://www.scielo.br/pdf/ rap/v44n3/o2.pdf $>$. Acesso em: 10 de fevereiro de 2018.

MEZA, M. L. F. G. Empreendedorismo público: discutindo seus níveis de análise. SILVA, Christian L. da (Org.) Políticas Públicas e Desenvolvimento Local: instrumentos e proposições de análise para o Brasil. Petrópolis, RJ: Vozes, 2012.

ROCHA, H. STERNBERG, R. Entrepreneurship and Development: The Role of Clusters. Small Business Economics, v. 23, n. 5, p. 363-400, 2005.

SEBRAE. Guia do Prefeito Empreendedor - Gestão Municipal 2013-2016. 10 passos e 100 ações - Agenda 
de Compromissos com os Pequenos Negócios para a

Geração de Emprego e Renda. Brasília: Sebrae, 2013.

SEBRAE. Regulamento do Prêmio Sebrae Prefeito Empreendedor. Disponível em: $<$ https://www.prefeitoempreendedor.sebrae. com.br/regulamento/>. Acesso em: 1o de fevereiro de 2018. 